\title{
ERRATA
}

\section{STM OBSERVATION OF GRATING SURFACES}

\author{
[MOD. PHY. LETT. B, Vol. 4, No. 3 (1990) 181 -193]
}

T. OSHIO, Y. SAKAI, S. EHARA, and K. TAKASHIMA

\author{
On page 184 \\ line 9 should read \\ $\theta$ is the obverse portion .... \\ On page 185 \\ line 4 should read \\ .... are drawn assumed to be the respective planes.
}

\author{
On page 185 \\ line 3 from the bottom should read
}

$\ldots$ in Fig. 7, and the STM image of the same grating is shown in Fig. 8. . .

On page 186

Table 1 should read 


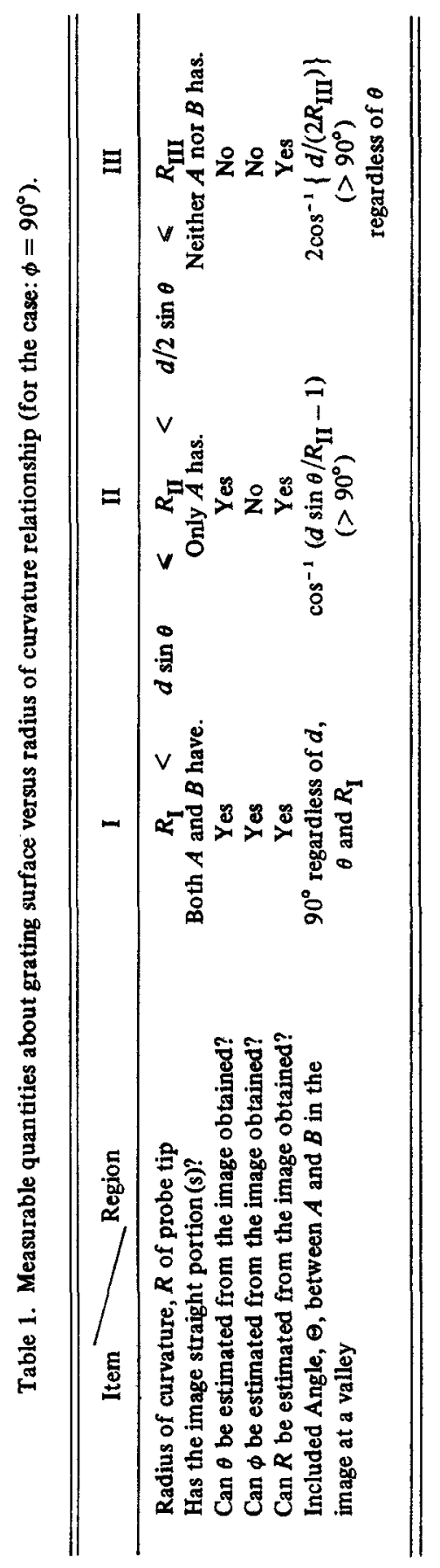

